\title{
Corticotroph hyperplasia and Cushing disease: diagnostic features and surgical management
}

\author{
Michael P. Catalino, MD, MSc, 1,2 David M. Meredith, MD, PhD,,3 Umberto De Girolami, MD, 3,4 \\ Sherwin Tavakol, MPH, ${ }^{1,5}$ Le Min, MD, PhD, ${ }^{6}$ and Edward R. Laws Jr., MD ${ }^{1,4}$
}

1Department of Neurosurgery, Brigham and Women's Hospital/Harvard Medical School, Boston, Massachusetts; ${ }^{2}$ Department
of Neurosurgery, University of North Carolina Hospitals, Chapel Hill, North Carolina; ${ }^{3}$ Department of Pathology, Brigham and
Women's Hospital/Harvard Medical School, Boston; ' ${ }^{4}$ Dana Farber Cancer Institute, Boston; ${ }^{5} \mathrm{H}$ arvard TH Chan School of Public
Health, Boston; and ${ }^{6}$ Division of Endocrinology, Brigham and Women's Hospital/Harvard Medical School, Boston, Massachusetts

OBJECTIVE This study was done to compare corticotroph hyperplasia and histopathologically proven adenomas in patients with Cushing disease by analyzing diagnostic features, surgical management, and clinical outcomes.

METHODS Patients with suspected pituitary Cushing disease were included in a retrospective cohort study and were excluded if results of pathological analysis of the surgical specimen were nondiagnostic or normal. Cases were reviewed by two experienced neuropathologists. Total lesion removal was used as a dichotomized surgical variable; it was defined as an extracapsular resection (including a rim of normal gland) in patients with an adenoma, and for hyperplasia patients it was defined as removal of the presumed lesion plus a rim of surrounding normal gland. Bivariate and multivariate analyses were performed. Recurrence-free survival was compared between the two groups.

RESULTS The final cohort consisted of 63 patients ( 15 with hyperplasia and 48 with adenoma). Normal pituitary acinar architecture was highly variable. Corticotroph hyperplasia was diagnosed based on the presence of expanded acini showing retained reticulin architecture and predominant staining for adrenocorticotropic hormone. Crooke's hyaline change was seen in $46.7 \%$ of specimens, and its frequency was equal in nonlesional tissue of both groups. The two groups differed only by MRI findings (equivocal/diffuse lesion in $46 \%$ of hyperplasia and $17 \%$ of adenoma; $p=0.03$ ). Diagnostic uncertainty in the hyperplasia group resulted in additional confirmatory testing by 24-hour urinary free cortisol. Total lesion removal was infrequent in patients with hyperplasia compared to those with adenoma ( $33 \%$ vs $65 \% ; p=$ 0.03). Initial biochemical remission was similar ( $67 \%$ in hyperplasia and $85 \%$ in adenoma; $p=0.11)$. There was no difference in hypothalamic-pituitary-adrenal axis recovery or disease recurrence. The median follow-up was 1.9 years (IQR 0.7-7.6 years) for the hyperplasia group and 1.2 years (IQR 0.4-2.4 years) for the adenoma group. Lack of a discrete lesion and diagnostic uncertainty were the only significant predictors of hyperplasia (sensitivity $53.3 \%$, specificity $97.7 \%$, positive predictive value $88.9 \%$, negative predictive value $85.7 \%$ ). An adjusted Cox proportional hazards model showed similar recurrence-free survival in the two groups.

CONCLUSIONS This study suggests an association between biochemically proven Cushing disease and histopathologically proven corticotroph hyperplasia. Imaging and operative findings can be ambiguous, and, compared to typical adenomas with a pseudocapsule, the surgical approach is more nuanced. Nevertheless, if treated appropriately, biochemical outcomes may be similar.

https://thejns.org/doi/abs/10.3171/2020.5.JNS201514

KEYWORDS Cushing disease; corticotroph hyperplasia; corticotroph adenoma; diagnosis; pathology; surgical outcomes; pituitary surgery

$\mathrm{H}$ ISTOPATHOLOGY in patients with Cushing disease is frequently inconsistent, even in those with biochemical remission. ${ }^{1-4}$ Normal pituitary gland, corticotroph hyperplasia, and corticotroph adenomas, including pseudoencapsulated adenomas, can all be en- countered.$^{4-7}$ Crooke's hyaline change, which is a morphological indicator of corticotroph inhibitory feedback, may be detected in the adjacent normal gland. ${ }^{4}$ Although the diagnosis and subsequent management of corticotroph hyperplasia is the most challenging, it provides insight into

ABBREVIATIONS ACTH = adrenocorticotropic hormone; $\mathrm{CRH}=$ corticotropin-releasing hormone; HPA = hypothalamic-pituitary-adrenal; HR = hazard ratio; IPSS = inferior petrosal sinus sampling; ROC = receiver operating characteristic; UFC = urinary free cortisol.

SUBMITTED April 28, 2020. ACCEPTED May 21, 2020.

INCLUDE WHEN CITING Published online September 4, 2020; DOI: 10.3171/2020.5.JNS201514. 
the pathophysiological mechanisms underlying Cushing disease. Neither the inciting stimulus nor the pathogenesis of corticotroph hyperplasia-neoplasia transformation has been adequately described despite their temporal relationship observed in case reports and in our own series (Table 1 , case 10$)^{6}$

Cushing disease is caused by elevated serum cortisol with loss of diurnal variation because of the autonomous overproduction of adrenocorticotropic hormone (ACTH) from a benign corticotroph adenoma within the pituitary gland. ${ }^{8}$ Selective surgical removal of the tumor, if identified, has been an effective primary treatment, but late recurrences can occur in up to $25 \%$ of patients with long-term follow-up. ${ }^{9,10}$ In the absence of a corticotroph adenoma, the diagnosis of corticotroph hyperplasia can be considered. Previous reports conclude that corticotroph hyperplasia is the polyclonal expansion of corticotrophs within expanded but architecturally intact acini (as demonstrated by reticulin staining).$^{11}$ In comparison, monoclonal expansion and disruption of the acinar architecture is characteristic of pituitary adenomas..$^{12}$ Although typical of other pituitary cell lines, corticotroph hyperplasia may not be uniformly polyclonal given the presence of very small islands of tumor that can occur in rare cases. Corticotroph hyperplasia is unique because it only rarely associates with ectopic corticotropin-releasing hormone (CRH)-secreting tumors. ${ }^{13,14}$ Therefore, the term "primary corticotroph hyperplasia" has been used to refer to pituitary corticotroph hyperplasia caused by elevated hypothalamic CRH secretion or overly sensitive corticotroph CRH receptors. ${ }^{15}$ Historically, two separate considerations explain the pathogenesis of corticotroph adenomas. ${ }^{16,17}$ One position proposes that a neoplastic change in the pituitary gland occurs, and thus microsurgery for removal is an effective treatment. The other argues that hyperplastic change is driven by hypothalamic dysfunction, which subsequently progresses to an adenoma. In the latter condition, goals of treatment would include the development of a medical therapy to normalize hypothalamic output. In order to optimize the management of Cushing disease, the histopathological entities must be described in more detail, and, to date, a thorough clinicopathological analysis of hyperplasia has not been performed. Furthermore, we are concerned that many overlook the diagnosis of corticotroph hyperplasia and report it as normal gland.

In this study, we rigorously compare corticotroph hyperplasia to proven corticotroph adenomas in patients with Cushing disease in order to contextualize hyperplasia as a diagnosis and to report outcomes in the largest series to date. Our initial goal was to compare features of the diagnosis from an experienced center. Our second objective was to compare surgical outcomes.

\section{Methods \\ Patient Population}

We performed a retrospective cohort study. Patients were identified through an institutional database covering 2009 to 2019. One additional patient with hyperplasia was identified through clinical follow-up. Data were collected by chart review. All patients with biochemically suspected pituitary Cushing disease were included; patients were ex- cluded if pathological analysis of the surgical specimen was nondiagnostic or normal. We reviewed available nonlesional tissue for Crooke's changes. Institutional review board approval was obtained.

The criteria for diagnosis of hypercortisolism included typical signs and symptoms and at least two of the following biochemical test results: elevated 24-hour urinary free cortisol (UFC), elevated late-night salivary cortisol, and a failed 1-mg dexamethasone suppression test. ${ }^{18}$ When Cushing disease was suspected, MRI including highresolution small-field T1-weighted pre- and postcontrast images (sagittal and coronal) of the pituitary with 3-mm slice thickness was performed. Dynamic imaging was not routinely performed. In 2 patients with hyperplasia, the MRI data were missing. Inferior petrosal sinus sampling (IPSS) of ACTH after administration of bovine CRH was usually performed if imaging findings were ambiguous. During pathology review, 4 autopsy-derived specimens of the intact pituitary gland were analyzed for the purposes of normal histological control. Blinding was not possible due to the authors' collective experience with the cases. All hyperplasia cases and age- and sex-matched randomly selected corticotroph adenomas underwent unblinded rereview by two experienced neuropathologists to confirm study diagnoses and were compared to autopsy-derived normal pituitary gland controls.

\section{Disease Remission}

Remission was individually defined as resolution of hypercortisolemia as evidenced by either inpatient nadir cortisol $\leq 5$ with symptoms of adrenal insufficiency, nadir cortisol $\leq 2$ without symptoms, or normal 24-hour UFC performed as an outpatient test during follow-up. ${ }^{19}$ Recurrence was defined as initial remission with symptomatic and/or biochemical recurrence of Cushing disease by the above inclusion criteria. Patients entered the cohort at surgery and exited the cohort due to death (none), recurrence, or censoring at last follow-up.

\section{Data Analysis}

Initially we compared diagnostic features. Immunohistochemistry was performed on 5- $\mu \mathrm{m}$ formalin-fixed paraffin-embedded tissue sections by using antibodies against ACTH (Dako clone M3501), and reticulin staining was performed to assess acinar architecture. Symptoms, imaging, biochemical evaluations, and outcome data were extracted from medical records and compared between the two groups by using bivariate analyses. The MannWhitney U-test was used for nonparametric continuous variables and the chi-square test for categorical variables. If the cell number was $<5$, a 2 -sided Fisher exact test was performed. Total lesion removal was a dichotomized surgical variable defined by intraoperative impression of extracapsular resection (including a rim of normal gland) in patients with an adenoma, and for patients with hyperplasia, the removal of the presumed lesion plus a rim of surrounding normal gland. Total lesion removal also included 8 patients who had a subtotal hypophysectomy $(2$ with hyperplasia and 6 with adenoma). In order to understand predictors of final histopathological findings, pur- 
TABLE 1. Detailed clinical, symptom, biochemical, operative, and remission characteristics in 15 patients with corticotroph hyperplasia

\begin{tabular}{|c|c|c|c|c|c|c|c|c|c|c|}
\hline $\begin{array}{l}\text { Case } \\
\text { No. }\end{array}$ & $\begin{array}{l}\text { Age } \\
\text { (yrs)/ } \\
\text { Sex }\end{array}$ & Redo & Signs \& Symptoms & $\begin{array}{l}\mathrm{BMl} \\
(\mathrm{kg} / \\
\left.\mathrm{m}^{2}\right)\end{array}$ & Labor & ratory Results* & IPSS & Operation & $\begin{array}{l}\text { Nadir } \\
\text { Cortisol }\end{array}$ & Remission \\
\hline 1 & $35 / F$ & No & $\begin{array}{l}\text { Blurry vision, memory loss, insomnia, lost } \\
\text { words, difficulty w/ math, palpitations }\end{array}$ & M & $\begin{array}{l}\text { ACTH 101; } \\
\text { Cort } 19\end{array}$ & UFC $(+)(+) ;$ DST $(+)$ & C & TLR & M & Yest \\
\hline 2 & $32 / F$ & Yes & $\begin{array}{l}\text { Weight gain, hirsutism, mood lability, insom- } \\
\text { nia, irregular periods, memory loss, ankle } \\
\text { swelling }\end{array}$ & M & $\begin{array}{r}\text { ACTH 55; } \\
\text { Cort } 22\end{array}$ & UFC $(+)(+) ;$ DST $(+)$ & C & PLR & M & Yest \\
\hline 3 & $42 / \mathrm{M}$ & Yes & $\begin{array}{l}\text { Uncontrolled DM, supraclavicular fat pad, } \\
\text { inability to lose weight }\end{array}$ & 51 & M & $\begin{array}{l}\text { UFC }(+)(+)(+)(+) \\
\text { DST }(-)\end{array}$ & NP & PLR & M & Yes† \\
\hline 4 & $59 / \mathrm{M}$ & Yes & $\begin{array}{l}\text { Weight gain, weakness, supraclavicular fat } \\
\text { pad, delayed cognitive processing, loss of } \\
\text { libido, fatigue }\end{array}$ & 34 & $\begin{array}{r}\text { ACTH } 37 ; \\
\text { Cort } 22\end{array}$ & UFC $(+)(+)$ & C & PLR & 1.0 & Yes \\
\hline 5 & $33 / F$ & Yes & $\begin{array}{l}\text { Uncontrolled DM \& HTN, obesity, emotional } \\
\text { lability, dorsal cervical \& supraclavicular fat } \\
\text { pad, abdominal striae, acne, easy bruising }\end{array}$ & 27 & $\begin{array}{l}\text { ACTH 164; } \\
\text { Cort } 30\end{array}$ & UFC $(+)$ & NP & TLR & 9.7 & No \\
\hline 6 & $35 / F$ & No & $\begin{array}{l}\text { Fatigue, easy bruising, uncontrolled HTN, } \\
\text { weight gain }\end{array}$ & 36 & $\begin{array}{r}\text { ACTH 25; } \\
\text { Cort } 30\end{array}$ & $\begin{array}{l}\text { UFC (+); LNSC (+); } \\
\text { DST (+) }\end{array}$ & C & TLR & 26.3 & No \\
\hline 7 & $19 / \mathrm{M}$ & No & $\begin{array}{l}\text { Candida infection, violaceous axillary striae, } \\
\text { centripetal obesity, supraclavicular fat pad, } \\
\text { easy bruising }\end{array}$ & 25 & $\begin{array}{l}\text { ACTH 109; } \\
\quad \text { Cort } 27\end{array}$ & $\begin{array}{l}\text { UFC }(+)(+)(+)(+) \\
\quad \text { DST }(+)\end{array}$ & $? \ddagger$ & PLR & 21.1 & No§ \\
\hline 8 & $43 / \mathrm{M}$ & No & $\begin{array}{l}\text { Nothing obvious, inability to lose weight, head- } \\
\text { aches, borderline DM, low testosterone }\end{array}$ & 33 & $\begin{array}{r}\text { ACTH 26; } \\
\text { Cort } 13\end{array}$ & $\begin{array}{l}\text { UFC }(+)(+)(+) ; \text { LNSC } \\
(+)(+) ; \text { DST }(+)\end{array}$ & NP & PLR & 5.7 & Yes \\
\hline 9 & $36 / F$ & Yes & $\begin{array}{l}\text { Weight gain, hair thinning, easy bruising \& } \\
\text { bleeding, fatigue, hirsutism, dorsal cervical } \\
\text { \& supraclavicular fat pad }\end{array}$ & 48 & $\begin{array}{l}\text { ACTH 112; } \\
\text { Cort } 27\end{array}$ & UFC (-); DST (+) & NP & PLR & 16.1 & No \\
\hline 10 & $15 / \mathrm{M}$ & No & $\begin{array}{l}\text { Acne, alopecia w/ facial/trunk hair growth, } \\
\text { centripetal obesity, striae, decreased } \\
\text { growth rate }\end{array}$ & 28 & $\begin{array}{r}\text { ACTH } 87 \\
\text { Cort } 36\end{array}$ & UFC (+); LNSC (+) & C & PLR & 15.1 & No \\
\hline 11 & $44 / F$ & No & $\begin{array}{l}\text { Difficulty losing centripetal weight after cesar- } \\
\text { ean section, heat intolerance, HTN, mood } \\
\text { lability, insomnia, headache }\end{array}$ & 33 & $\begin{array}{r}\text { ACTH 18; } \\
\text { Cort } 19\end{array}$ & $\begin{array}{l}\text { UFC }(+)(+) ; \text { LNSC } \\
(+)(+) ; \text { DST }(+)\end{array}$ & C & PLR & 4.1 & Yes \\
\hline 12 & $38 / F$ & No & $\begin{array}{l}\text { Weight gain, headache, depression, irritability, } \\
\text { fractures }\end{array}$ & 35 & $\begin{array}{r}\text { ACTH 98; } \\
\text { Cort } 24\end{array}$ & UFC $(+)(+) ;$ DST $(+)$ & NP & PLR & 3.2 & Yes \\
\hline 13 & $18 / \mathrm{M}$ & No & $\begin{array}{l}\text { Uncontrolled HTN, morbid centripetal obesity, } \\
\text { hypogonadism, memory loss, mood lability, } \\
\text { anxiety, fractures, increased face \& body } \\
\text { hair, striae, blurry vision, skin thinning, easy } \\
\text { bruising, increased flushing/sweating }\end{array}$ & 48 & $\begin{array}{l}\text { ACTH 22; } \\
\quad \text { Cort } \\
4.3\end{array}$ & UFC (+); DST (+) & NP & PLR & 9.0 & Yesग \\
\hline 14 & $33 / F$ & No & $\begin{array}{l}\text { Weight gain, fatigue, inability to focus, ir- } \\
\text { ritable, centripetal obesity, hirsutism, acne, } \\
\text { striae }\end{array}$ & 48 & $\begin{array}{r}\text { ACTH 14; } \\
\text { Cort } 33\end{array}$ & $\begin{array}{l}\text { UFC (+); LNSC (-) } \\
(-)(+)(+) ; \text { DST }(-)\end{array}$ & C & TLR & 12.4 & Yes** \\
\hline 15 & $59 / F$ & No & $\begin{array}{l}\text { Hirsutism, dorsal cervical fat pad, supraclavic- } \\
\text { ular fat pad, striae, easy bruising, thin skin, } \\
\text { moon facies, facial plethora, alopecia }\end{array}$ & 39 & $\begin{array}{l}\text { ACTH 46; } \\
\text { Cort } \\
11.8\end{array}$ & $\begin{array}{l}\text { UFC (-); LNSC }(+) \\
(-)(-)(-) ; \text { DST }(+)\end{array}$ & C & TLR & 1.5 & Yes \\
\hline
\end{tabular}

$\mathrm{C}=$ pituitary source; Cort = cortisol; $\mathrm{DM}=$ diabetes mellitus; $\mathrm{DST}=$ low-dose dexamethasone suppression test; HTN = hypertension; LNSC = late-night salivary cortisol; $\mathrm{M}=$ missing; $\mathrm{NP}=$ not performed-lateralization data were not reliable; PLR = partial lesion removal as observed intraoperatively due to diffuse nature; TLR = total lesion removal-presumed lesion removal plus rim of surrounding normal gland, includes subtotal hypophysectomy (cases 1 and 14).

The patient in case 10 did not enter remission, and subsequent surgery revealed a corticotroph adenoma.

* ACTH (in pg/mL) and cortisol (in $\mu \mathrm{g} / \mathrm{dL}$ ) are reported as nearest preoperative morning fasting values; $(+)$ or $(-)$ represents single elevated/not elevated UFC test; (+) or (-) represents unsuppressed/suppressed cortisol with overnight low DST; and (+) or (-) represents a single elevated/not elevated LNSC test. (+)(+) or (-)(-) means 2 elevated/not elevated UFC results (same for other tests), and so on.

$†$ Remission status based on postoperative notes by endocrinology and neurosurgery. No laboratory values were available to confirm results. $\ddagger$ Uncertain; abnormal anatomy limited ability to interpret the results.

$\S$ This patient was found to have an ectopic source (lung) that was identified by FDG-PET and resected with robust hypocortisolemic remission by 8 PM the day of surgery.

I This patient had symptoms of adrenal insufficiency the day after discharge and was started on hydrocortisone replacement with good effect.

** During follow-up this patient displayed dramatic reversal of symptoms and had at least 2 normal LNSC tests. 
poseful selection was used to build an adjusted multivariate logistic regression model (bivariate $\mathrm{p}$ value $\leq 0.25$ for candidate predictor list, beta coefficient change by $\geq 20 \%$, or adjusted $\mathrm{p}$ value $\leq 0.1$ for final model). Odds ratios with $95 \%$ confidence intervals and $\mathrm{p}$ values are reported, as well as results from a receiver operating characteristic (ROC) analysis.

Second, we compared outcomes between the two groups. Similar to our initial goal, a multivariate logistic regression model was generated for remission. An adjusted Cox proportional hazards model was used to compare recurrence-free survival. The proportional hazards assumption was assessed and confirmed using Schoenfeld residual plots. Data analysis was performed in Stata (StataCorp.).

\section{Results \\ Diagnostic Features}

The final cohort consisted of 63 patients (15 with hyperplasia and 48 with adenoma). No patients with hyperplasia were excluded. There were 32 other patients excluded because of negative pathology results $(\mathrm{n}=11)$, incomplete postoperative cortisol data $(\mathrm{n}=19)$, negative ACTH staining $(\mathrm{n}=1)$, and malignant tumor phenotype $(\mathrm{n}=1)$. Figure 1 shows an example of the typical histopathological findings in a patient with corticotroph hyperplasia compared to both normal pituitary gland and corticotroph adenoma, in which $\mathrm{H} \& \mathrm{E}$, reticulin, and ACTH staining were used. Compared to normal pituitary architecture (Fig. 1G-I), all cases of hyperplasia demonstrated expanded acini with preserved reticulin architecture that also exhibited homogeneous immunopositivity for ACTH (Fig. 1D-F). Neither the degree of expansion nor the homogeneity of ACTH staining observed in cases of hyperplasia was as evident in autopsy control tissue despite considerable variability in acinar size. We agree that the absence or presence of compressed adjacent normal gland is of uncertain significance, and it may represent a continuum with the formation of a pseudocapsule. ${ }^{7,20,21}$ In adenomas, the reticulin architecture was significantly disrupted or absent, and ACTH immunostaining was diffusely positive in all cases. Crooke's hyaline change was present in the age- and sex-matched hyperplasia and adenoma cohorts, occurring with equal frequency in nonlesional tissue $(7 / 15,46.7 \%$ in both groups). Three adenoma patients did not have available nonlesional tissue to review. Furthermore, one case of adenoma exhibited significant Crooke's change and was reclassified as Crooke cell adenoma.

The series of patients with hyperplasia is included in Table 1. Preoperative and postoperative features of hyperplasia and adenoma are compared in Tables 2 and 3, respectively. Preoperatively, the two groups were similar except for imaging. Equivocal or diffuse findings on MRI were more common in patients with hyperplasia ( $46 \%$ vs $17 \%$; $p$ $=0.03$ ). More UFC tests were abnormal in the hyperplasia group (53\% vs $2 \%$ had $\geq 2$ abnormal results; $\mathrm{p}<0.001$ ), which probably reflects underlying diagnostic uncertainty requiring additional confirmatory testing. This is supported by the trend toward more IPSS studies performed in the hyperplasia group (60\% vs $37 \%$; $p=0.12$ ). Figure 2 shows the results of the age- and sex-matched comparison of MRI findings and classification of discrete and diffuse lesions.
An equivocal/diffuse lesion on the MRI was a significant predictor of hyperplasia (OR 7.3, 95\% CI 1.4-38.0; $\mathrm{p}=0.019$; Table 4). Purposeful selection obligated inclusion of what we define as UFC (or diagnostic) uncertainty, which proved to be a significant confounder and was associated with increased odds of having hyperplasia (OR 56.6, 95\% CI 5.2-610.4; $\mathrm{p}=0.001$ ). There was no effect modification between equivocal/diffuse lesion on MRI and the number of 24-hour UFC studies on the odds of recurrence. ROC analysis revealed a sensitivity of 53.3\%, specificity of $97.7 \%$, positive predictive value of $88.9 \%$, negative predictive value of $85.7 \%$, and area under the ROC curve of 0.85 for predicting hyperplasia. These features correctly classified pathology in $86.2 \%$ of patients.

\section{Outcomes}

Surgical outcomes were compared between the two groups. Table 3 provides information on surgical and postoperative characteristics. As expected, total lesion removal was infrequent in patients with hyperplasia compared to adenoma ( $33 \%$ vs $65 \% ; p=0.03$ ), median nadir cortisol was higher ( $9.4 \mathrm{vs} 2.8 \mu \mathrm{g} / \mathrm{dL} ; \mathrm{p}=0.01$ ), and median hours to nadir cortisol was greater in the hyperplasia group (61.5 vs 27 hours; $p=0.01$ ). Initial biochemical remission was similar but trended lower in the hyperplasia group $(67 \%$ vs $85 \% ; \mathrm{p}=0.11$ ), and both nadir cortisol and hours to nadir were similar among patients with initial remission. Figure 3 shows detailed postoperative cortisol dynamics in age- and sex-matched patients from each group. Recovery of the hypothalamic-pituitary-adrenal (HPA) axis was no different between the groups as measured by duration of time receiving glucocorticoid replacement in patients with persistent remission (Table 3). Recurrent disease had occurred in $20 \%$ of the hyperplasia group and $15 \%$ of the adenoma group at last follow-up (see adjusted KaplanMeier estimates below). The median follow-up time was 1.9 years (IQR 0.7-7.6 years) for the hyperplasia group and 1.2 years (IQR 0.4-2.4 years) for the adenoma group.

No pre- or postoperative variables correlated with remission in a multivariate analysis. Nadir cortisol was excluded as a candidate predictor because nadir values often defined the outcome. The Cox proportional hazards model by pathological subtype was adjusted for revision surgery. Kaplan-Meier recurrence-free survival was estimated (Fig. 4) and showed no difference between the groups (hazard ratio [HR] for adenoma $0.80,95 \% \mathrm{CI} 0.16-4.05 ; \mathrm{p}=0.76$ ). The study was powered to detect an HR of $\leq 0.46$ (power $\geq 0.8$ ).

\section{Discussion}

In this study we compared the diagnostic features and outcomes of corticotroph hyperplasia and corticotroph adenoma. Here we describe three major advancements in the diagnosis of corticotroph hyperplasia. First, even for the trained clinician, corticotroph hyperplasia may explain some of the diagnostic uncertainty in patients presenting with Cushing disease. From our experience, this comes in many forms, such as conflicting laboratory findings. Therefore, we routinely repeat the 24-hour UFC test (or other biochemical tests) in order to ensure that at 


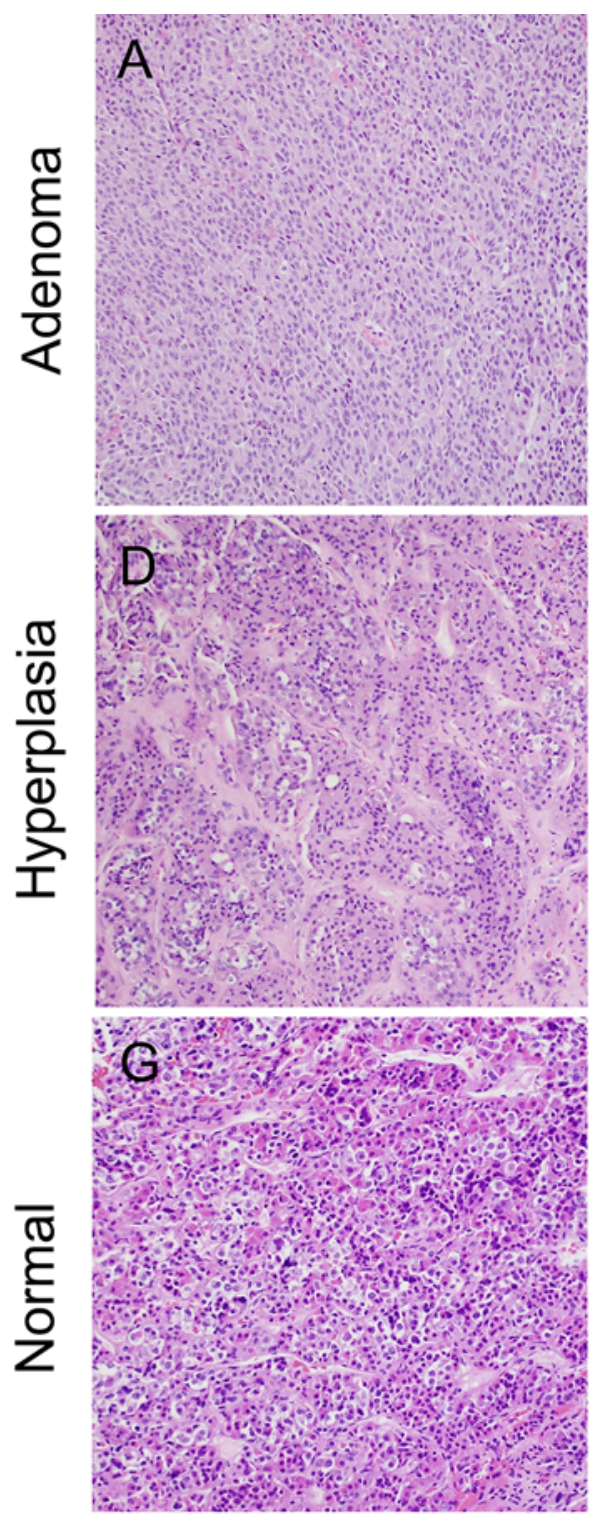

$H \& E$
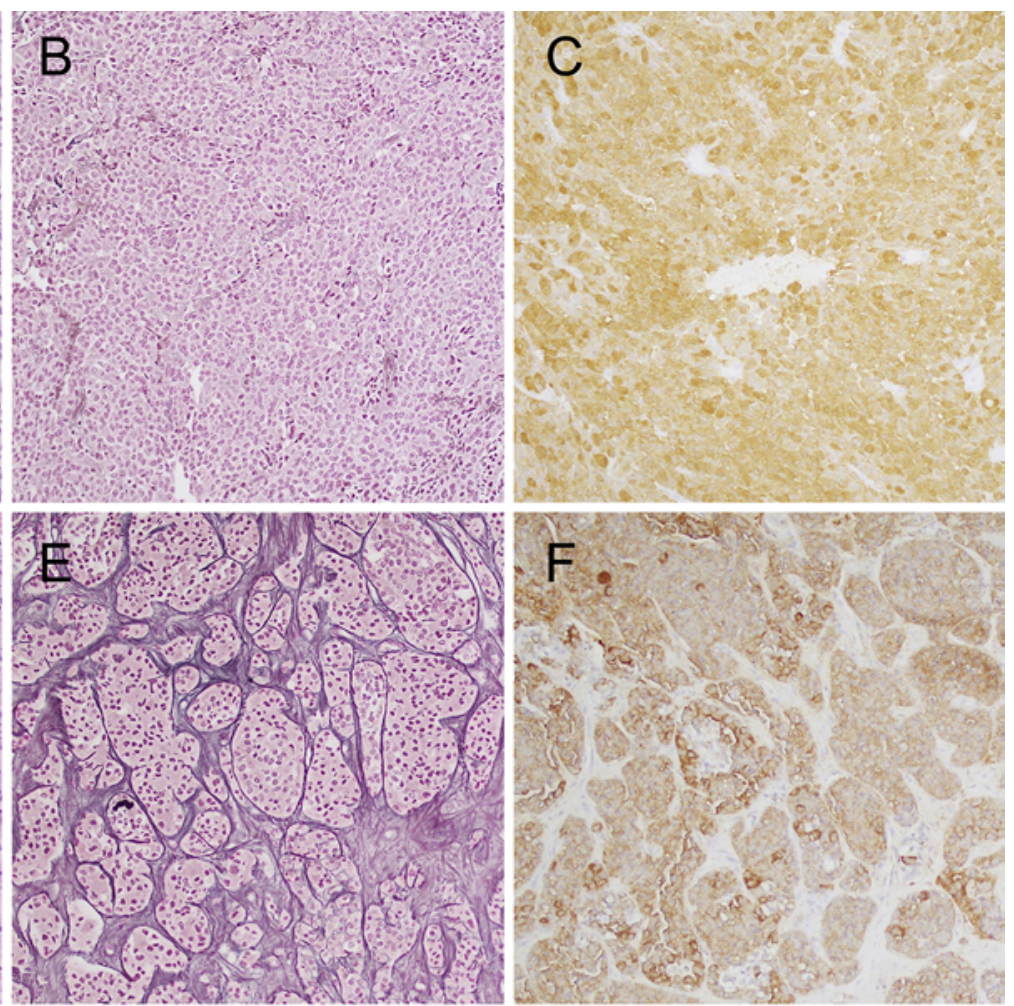

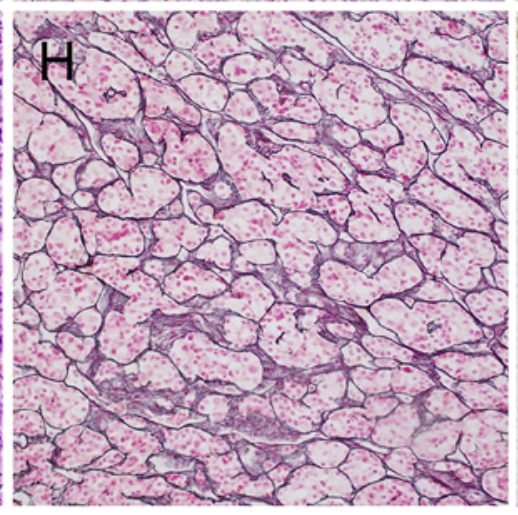

Reticulin

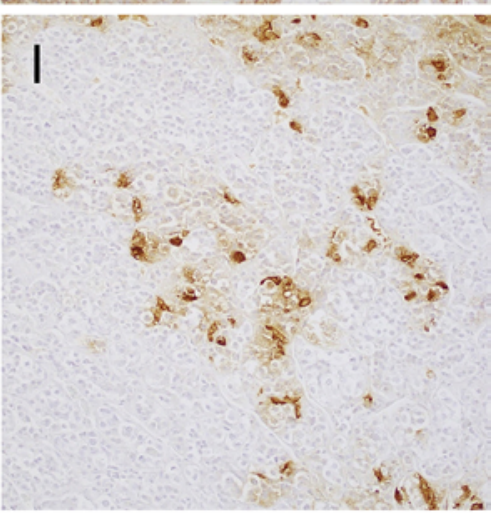

$\mathrm{ACTH}$

FIG. 1. A-C: Photomicrographs of samples of adenoma. A: H \& E stain shows monomorphic tumor cells with homogeneous appearance. B: Reticulin stain shows complete loss of acinar architecture. C: ACTH immunohistochemistry is diffusely positive. D-F: Photomicrographs of samples of hyperplastic tissue. D: H \& E stain showing islands of hyperplasia that appear uniformly basophilic with expanded acini. E: Reticulin stain shows that acinar architecture in islands of hyperplasia is preserved but is noticeably expanded compared to normal tissue. F: Islands of hyperplasia show uniform ACTH staining. G-I: Photomicrographs of samples of normal tissue. G: H \& E stain showing normal anterior pituitary tissue with heterogeneous distribution of acidophils, basophils, and chromophobe cell types. H: Reticulin stain highlights uniform acinar shape and size. I: ACTH staining is heterogeneous. Original magnification $\times 200$ for all panels. Figure is available in color online only.

least two results are abnormal. Second, patients with hyperplasia often have equivocal/diffuse findings on MRI. As shown in Fig. 2, this is often represented by diffuse T1 hypointensity and/or minimal enhancement relative to the normal pituitary gland. Focal areas are also observed, but these more discrete lesions were more frequently seen in patients with adenomas, and adenomas typically retain more T1 signal (although they are still hypointense to normal gland). Together, these two features correctly identified $86.2 \%$ of patients, but the absence of blinded re- view limits the generalizability of our results to those not accustomed to such cases. IPSS is essential for patients with ambiguous imaging studies and was performed more often in our hyperplasia group, further showing the need for additional confirmatory testing when the diagnosis of Cushing disease is uncertain. Our data are consistent with those of Semple et al., indicating that adenomas are often identified intraoperatively even with a negative MRI study. ${ }^{22}$ Finally, because we devoted much scrutiny to reexamining the initial pathological diagnoses, we mention 
TABLE 2. Preoperative characteristics in 63 patients with corticotroph hyperplasia or adenoma

\begin{tabular}{|c|c|c|c|}
\hline \multirow[b]{2}{*}{ Characteristic } & \multicolumn{2}{|c|}{ Pathology } & \multirow[b]{2}{*}{$\begin{array}{c}\mathrm{p} \\
\text { Value }\end{array}$} \\
\hline & $\begin{array}{l}\text { Hyperplasia, } \\
n=15\end{array}$ & $\begin{array}{l}\text { Adenoma } \\
n=48\end{array}$ & \\
\hline \multicolumn{4}{|l|}{$\operatorname{Sex}(\%)$} \\
\hline Male & $6 / 15(40 \%)$ & $10 / 48(21 \%)$ & 0.14 \\
\hline Female & $9 / 15(60 \%)$ & $38 / 48(80 \%)$ & \\
\hline Postpartum status (\%)* & $2 / 9(22 \%)$ & $8 / 38(21 \%)$ & 0.94 \\
\hline Age, median yrs (IQR) & $35(32-43)$ & $45(33-54)$ & 0.09 \\
\hline BMI, median $\mathrm{kg} / \mathrm{m}^{2}(\mathrm{IQR})$ & $35(33-48)$ & $34(30-40)$ & 0.34 \\
\hline $\begin{array}{l}\text { Symptoms, median yrs } \\
\text { (IQR) }\end{array}$ & $2(1-5)$ & $2(1-4)$ & 0.88 \\
\hline \multicolumn{4}{|l|}{ MRI findings (\%) } \\
\hline $\begin{array}{l}\text { Equivocal/diffuse } \\
\text { lesion }\end{array}$ & $6 / 13(46 \%)$ & $8 / 48(17 \%)$ & 0.03 \\
\hline Discrete lesion & $7 / 13(54 \%)$ & $40 / 48(83 \%)$ & \\
\hline \multicolumn{4}{|l|}{ Revision surgery (\%) } \\
\hline No & $10 / 15(67 \%)$ & $31 / 48(65 \%)$ & 0.88 \\
\hline Yes & $5 / 15(33 \%)$ & $17 / 48(35 \%)$ & \\
\hline \multicolumn{4}{|l|}{ Adrenal mass (\%) } \\
\hline No & $14 / 15(93 \%)$ & $41 / 48(85 \%)$ & 0.67 \\
\hline Yes & $1 / 15(7 \%)$ & $7 / 48(15 \%)$ & \\
\hline $\begin{array}{l}\text { ACTH, median } \mathrm{pg} / \mathrm{mL} \\
(\mathrm{IQR})\end{array}$ & $51(25-101)$ & $70(45-97)$ & 0.31 \\
\hline $\begin{array}{l}\text { AM cortisol, median } \mu \mathrm{g} / \\
\mathrm{dL}(\mathrm{IQR})\end{array}$ & $23(19-30)$ & $23(17-28)$ & 0.84 \\
\hline \multicolumn{4}{|l|}{ LNSC (\%) } \\
\hline 0-2 abnormal & $3 / 6(50 \%)$ & $16 / 25(64 \%)$ & 0.65 \\
\hline$>2$ abnormal & $3 / 6(50 \%)$ & 9/25 (36\%) & \\
\hline \multicolumn{4}{|l|}{ 24-hr UFC (\%) } \\
\hline$<2$ abnormal & $7 / 15(47 \%)$ & $42 / 43(98 \%)$ & $<0.001$ \\
\hline$\geq 2$ abnormal & $8 / 15(53 \%)$ & $1 / 43(2 \%)$ & \\
\hline \multicolumn{4}{|l|}{ DST (\%) } \\
\hline Not suppressed & 10/12 (83\%) & $26 / 29(90 \%)$ & 0.62 \\
\hline Suppressed & $2 / 12(17 \%)$ & $3 / 29(10 \%)$ & \\
\hline \multicolumn{4}{|l|}{ IPSS (\%) } \\
\hline No & $6 / 15(40 \%)$ & $30 / 48$ (63\%) & 0.12 \\
\hline Yes & $9 / 15(60 \%)$ & $18 / 48(37 \%)$ & \\
\hline Central (\%)† & $8 / 9(89 \%)$ & 18/18 (100\%) & 0.33 \\
\hline
\end{tabular}

Missing values indicated by denominator less than $\mathrm{N}$ for either group unless otherwise indicated. Proportions may not add up to $100 \%$ due to rounding. ${ }^{*}$ Females only.

† Among those with IPSS, the number with results suggestive of a central source of ACTH; laterality data unreliable.

a few key histopathological considerations (see Results). Here it is important to emphasize the preservation of precious surgical tissue for analysis. Corticotroph hyperplasia was diagnosed based on the presence of 1) significantly expanded acini showing intact architecture by reticulin staining, and 2) predominant staining for ACTH by immunohistochemistry. This is consistent with findings from case reports of corticotroph hyperplasia, and hyperplasia
TABLE 3. Operative and postoperative characteristics in 63 patients with corticotroph hyperplasia or adenoma

\begin{tabular}{|c|c|c|c|}
\hline \multirow[b]{2}{*}{ Characteristic } & \multicolumn{2}{|c|}{ Pathology } & \multirow[b]{2}{*}{$\begin{array}{c}p \\
\text { Value }\end{array}$} \\
\hline & $\begin{array}{l}\text { Hyperplasia, } \\
\quad n=15\end{array}$ & $\begin{array}{l}\text { Adenoma, } \\
n=48\end{array}$ & \\
\hline \multicolumn{4}{|l|}{ Operation (\%) } \\
\hline $\begin{array}{l}\text { Presumed lesion } \\
\text { removal }\end{array}$ & $10 / 15(67 \%)$ & $17 / 48(35 \%)$ & 0.03 \\
\hline Total lesion removal ${ }^{*}$ & $5 / 15(33 \%)$ & $31 / 48(65 \%)$ & \\
\hline $\begin{array}{l}\text { Cortisol nadir, median } \\
\mu \mathrm{g} / \mathrm{dL}(\mathrm{IQR})\end{array}$ & $9.4(3.6-15.6)$ & $2.8(1.4-5.4)$ & 0.01 \\
\hline Nadir, median hrs (IQR) & $61.5(30-71)$ & $27(15-48)$ & 0.01 \\
\hline \multicolumn{4}{|l|}{ Initial remission (\%) } \\
\hline No & $5 / 15(33 \%)$ & $7 / 48(15 \%)$ & 0.11 \\
\hline Yes & $10 / 15(67 \%)$ & $41 / 48(85 \%)$ & \\
\hline $\begin{array}{l}\text { Cortisol nadir, median } \\
\mu \mathrm{g} / \mathrm{dL}(\mathrm{IQR}) \dagger\end{array}$ & $4.1(1.5-9)$ & $2.3(1.2-3.6)$ & 0.12 \\
\hline Nadir, median hrs (IQR)† & $34(20-69)$ & $20(15-43)$ & 0.11 \\
\hline $\begin{array}{l}\text { Immediate cortisol } \\
\text { replacement (\%)† }\end{array}$ & $9 / 10(90 \%)$ & $38 / 41(93 \%)$ & 1.00 \\
\hline $\begin{array}{l}\text { Steroid time, median } \\
\text { wks (IQR) } \ddagger\end{array}$ & $15(5-341)$ & $36(14-63)$ & 0.79 \\
\hline HPA axis recovery $(\%) \dagger \S$ & $1 / 8(13 \%)$ & $13 / 34(38 \%)$ & 0.23 \\
\hline $\begin{array}{l}\text { Yrs of follow-up, median } \\
(\text { IQR)ף }\end{array}$ & $1.9(0.7-7.6)$ & $1.2(0.4-2.4)$ & 0.50 \\
\hline \multicolumn{4}{|l|}{ Recurrence (\%)† } \\
\hline No & $8 / 10(80 \%)$ & $35 / 41(85 \%)$ & 0.65 \\
\hline Yes & $2 / 10(20 \%)$ & $6 / 41(15 \%)$ & \\
\hline $\begin{array}{l}\text { Wks to recurrence, } \\
\text { median (IQR) }\end{array}$ & $64(51-76)$ & $21(9-141)$ & 0.51 \\
\hline \multicolumn{4}{|c|}{$\begin{array}{l}\text { Missing values are indicated by denominator less than } \mathrm{N} \text { for either group } \\
\text { subgroup) unless otherwise indicated. } \\
\text { * Presumed lesion removal plus rim of surrounding normal gland, which } \\
\text { includes subtotal hypophysectomy ( } 2 \text { hyperplasia; } 6 \text { adenoma). } \\
\text { † Among those with initial remission. } \\
\ddagger \text { Among those on cortisol replacement. } \\
\text { § HPA axis recovery at last follow-up among those still in remission. } \\
\text { † Among those who entered remission. }\end{array}$} \\
\hline
\end{tabular}

in other pituitary cell lines. ${ }^{21,23,24}$ Crooke's changes were seen in nonlesional hyperplasia specimens at the same frequency $(46.7 \%)$ as in the adenoma group. This frequency is lower than that reported by others and probably correlates with UFC levels. ${ }^{25}$

Surgical outcomes were similar between the two groups. Five patients (33\%) with corticotroph hyperplasia did not enter remission after surgery. The patients in cases 5 and 6 had nadir cortisol levels of 9.7 and 26.3, respectively, and both patients were lost to follow-up. The patient in case 7 was later diagnosed as having an ACTHsecreting neuroendocrine tumor of the lung that was initially missed on chest imaging, but entered remission after its removal. The patient in case 9 underwent a third-time revision for nonremission; her cortisol nadir was 16.1, and within 1 month after surgery she had two elevated latenight salivary cortisol levels. Finally, the patient in case 10 
A
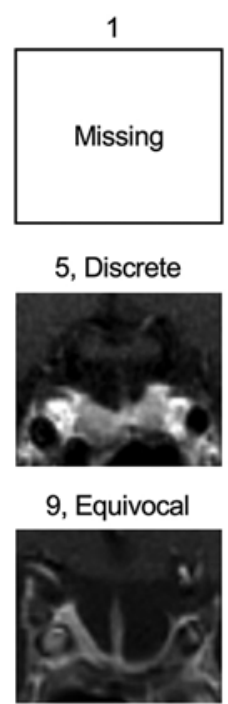

13, Diffuse

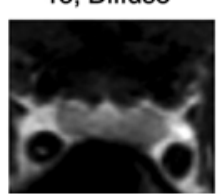

Hyperplasia

2, Discrete

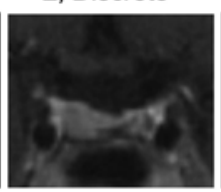

6, Diffuse

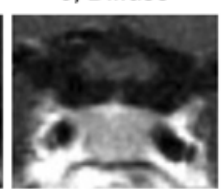

10, Diffuse

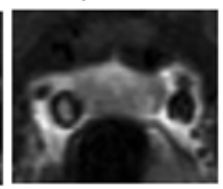

14, Discrete

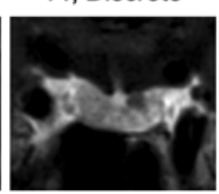

3

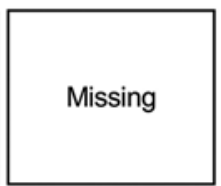

7, Diffuse

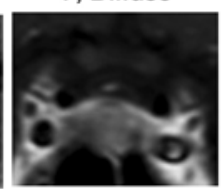

11, Discrete

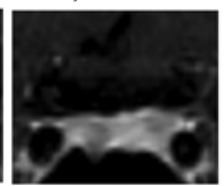

15, Discrete

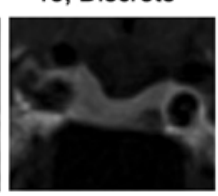

B

\section{4, Equivocal}

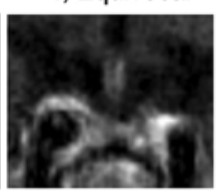

8, Discrete

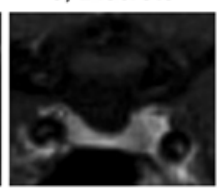

12, Discrete
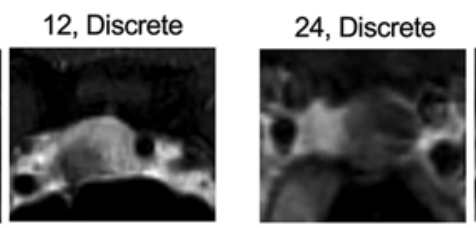

28, Discrete
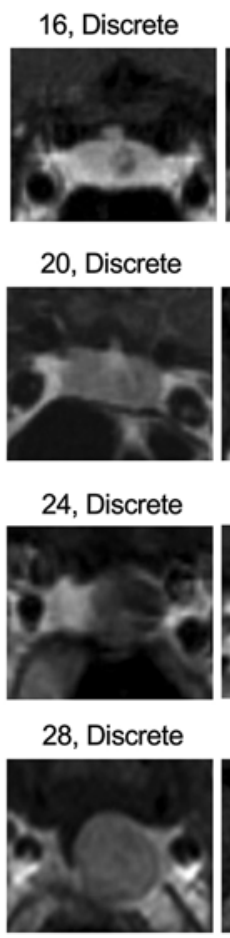

Adenoma
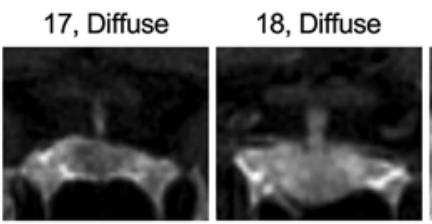

19, Discrete
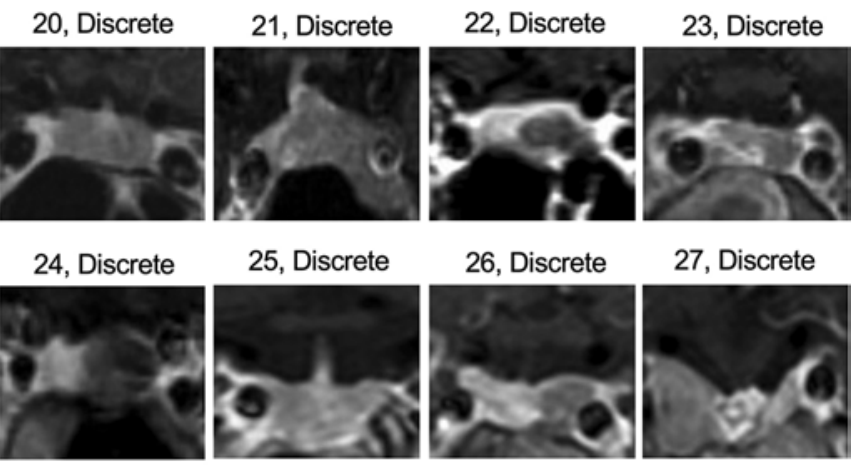

29, Discrete

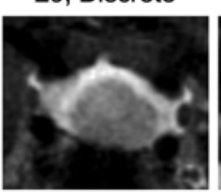

26, Discrete

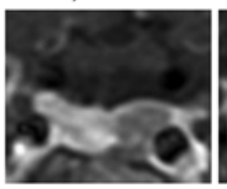

27, Discrete

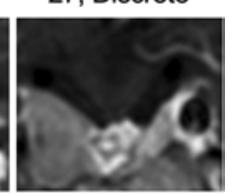

30, Discrete

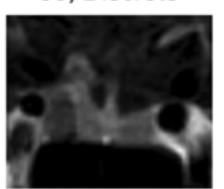

FIG. 2. Radiographic findings in patients with corticotroph hyperplasia (A) and age- and sex-matched corticotroph adenoma (B). Coronal T1-weighted postgadolinium MRI is shown. The case number corresponds to Table 1 for the hyperplasia group and is shared between Figs. 2 and 3 (both panels). Designation as an equivocal, diffuse, or discrete lesion is shown above each image.

did not enter remission after the first operation but eventually had corticotroph adenoma found during surgery a few months later. We adjusted for revision surgery because, as others have shown, it can confound remission outcomes. ${ }^{26}$ Cortisol nadir level and remission seemed highly variable in patients with hyperplasia. The predictive margins and 95\% confidence intervals were reviewed for nadir cortisol level and probability of remission. This showed substantial variation in the probability of remission (i.e., wide CIs) for both groups between nadir cortisol levels of 5 and $14 \mu \mathrm{g} / \mathrm{dL}$. The patients with hyperplasia, in general, had a higher nadir cortisol level and took longer to reach nadir levels (Table 3). However, this was not evident in the patients who ultimately entered remission. We hypothesize that hyperplasia and adenomas possess unique pathophysiological features relating to suppression of normal corticotrophs and thus may show differences in postoperative cortisol dynamics, ${ }^{27,28}$ but definitive conclusions cannot be drawn from our findings alone.

Two patients with hyperplasia had recurrences after initial remission. Both were diagnosed postpartum, representing the only 2 postpartum patients in the hyperplasia cohort. One patient (case 11) was started on pasireotide, and the other (case 12) was given ketoconazole after a subsequent failed operation performed elsewhere. They were both treated with proton-beam stereotactic radiosurgery (20 Gy). The patient in case 11 developed side effects from pasireotide (transaminitis and cholelithiasis), so it was discontinued after approximately 1 year. After one round of proton-beam stereotactic radiosurgery and 1 year of pasireotide, the patient improved clinically and is in biochemical remission. The patient in case 12 entered clinical and biochemical remission 1 year after radiation and is now off ketoconazole.

\section{Corticotroph Hyperplasia}

Hyperplasia and hyperplasia-adenoma transformation have been reported in Addison disease and Nelson syndrome. ${ }^{6,29,30}$ Our pathological findings in patients without Addison disease or Nelson syndrome were similar. Interestingly, one of our patients underwent two operations for Cushing disease, and each showed a different pathology (first hyperplasia, followed by adenoma; Fig. 3, cases 10 and 23). It is not clear, however, whether this represents a progression of the disease or a missed tumor at the first attempt. A visible lesion was identified and removed at the first operation, but the patient did not enter remission. In untreated Addison disease associated with presumed pituitary hyperplasia (i.e., enlargement of the pituitary gland on MRI and elevated ACTH levels), ACTH suppressed with a single small dose of dexamethasone. ${ }^{30}$ Our findings suggest that dexamethasone suppression is no different between the groups (Table 2).

Corticotroph hyperplasia has also been reported in children. Mustila et al. ${ }^{31}$ reported on a patient with typical symptoms of Cushing disease and a negative MRI. Total hypophysectomy resulted in sustained remission. ACTH hyperplasia was present throughout the pituitary gland, 
TABLE 4. Multivariate logistic regression for hyperplasia subtype

\begin{tabular}{ccrcc}
\hline Outcome & Covariate & OR & $p$ Value & $95 \% \mathrm{Cl}$ \\
\hline Hyperplasia & Equivocal/diffuse lesion & 7.3 & 0.019 & $1.4-38.0$ \\
\cline { 2 - 4 } & UFC uncertainty & 56.6 & 0.001 & $5.2-610.4$ \\
\hline
\end{tabular}

* Defined as requiring $\geq 2$ abnormal 24-hour UFC test results before surgery.

but nodules did exist in some areas. Noctor ${ }^{32}$ reported on a pediatric patient with cyclical Cushing disease, severe obesity, and a normal MRI. The first IPSS was equivocal, when the disease was not "active," and the second showed a central ACTH source during "active" disease (morning cortisol of $30.6 \mu \mathrm{g} / \mathrm{dL}$ ). A lesion was identified during surgery and removed. The patient was still being treated with corticosteroids at 1 year postoperatively and showed symptomatic improvement. There was diffuse ACTH positivity but a normal reticulin pattern. Noctor argues that diffuse ACTH positivity of apparent normal pituitary gland supports the presence of hyperplasia, given the absence of peripheral ACTH suppression from negative feedback, which should be present in an adenoma specimen if normal gland is visible. We did not have any pediatric patients in our cohort, but regarding the diagnosis of hyperplasia in that case, completely normal acinar architecture in such a patient should be questioned. Both expanded acinar architecture and a preponderance of ACTH staining within the expanded acini are important to make the diagnosis of hyperplasia. We show that the nodular foci of hyperplasia are usually surrounded by normal-appearing gland with heterogeneous ACTH immunopositivity (Fig. 1).

\section{Nuances of Pituitary Surgery in Cushing Disease}

Corticotroph pathology is fundamentally an intrinsic HPA axis pathology and, historically, there can be evidence of "basophilic invasion" of the neurohypophysis. ${ }^{33}$ Therefore, pituitary surgery for Cushing disease presents many challenges. ${ }^{34-36}$ The ideal situation is when the symptoms, MRI, and laboratory results together definitively suggest the presence of an ACTH-secreting pituitary adenoma. ${ }^{37}$ In this case, the surgical strategy is to search for the tumor and perform extracapsular resection if possible. If there is no encapsulated tumor, we resect the obvious lesion along with its peripheral margins and plan to preserve the posterior pituitary gland and its infundibular attachment. It is important to avoid a CSF leak by noting any arachnoidal diverticula and, after removal of the tumor, to search for a possible second tumor (rare). ${ }^{38}$

Problematic situations arise when the symptoms and laboratory results are not perfectly aligned, and the MRI finding is negative or merely suggestive, but nonetheless an IPSS is usually performed and is positive for a central ACTH source. The strategy in such cases is careful opening of the bony sella turcica-from one cavernous sinus margin to the other-and superior bony exposure a bit short of the tuberculum, avoiding any arachnoidal diverticula. The dura mater is opened in a cruciate or $\mathrm{X}$ incision ( $\mathrm{X}$ incision is generally preferred). Venous pressure is often elevated because of patient habitus, and venous bleeding from the dural incisions must be anticipated and either avoided or dealt with promptly to ensure adequate visualization. Cor- rect positioning of the patient to allow adequate venous drainage is critical to avoid such a scenario. Careful subdural dissection and reflection of the dural flaps is performed with assessment of pituitary gland consistency and turgor by gentle palpation using blunt dissectors. The anterior face of the pituitary gland is thoroughly exposed. If a probable lesion is encountered, the surgeon should remove it. If no lesion is visualized, and IPSS has been done and is reliable, the surgeon should consider a hemihypophysectomy guided by IPSS lateralization, if present.

Finally, there are situations in which there is probable Cushing disease, and imaging shows an equivocal/diffuse lesion suggesting ACTH hyperplasia. The strategy is to begin with careful subdural mobilization of both lateral lobes of the gland, feeling for a soft spot or visualized abnormality (e.g., color or texture). Histological corticotroph mapping has revealed that most ACTH cells are clustered in the anterior central mucoid wedge of the gland,,$^{39}$ which can become the target. With sharp dissection, we explore and resect the entire mucoid wedge and carry the dissection back to the pars intermedia (where some ACTH tumors originate)..$^{40}$ This must be done carefully, and without damage to the posterior pituitary or manipulation of the pituitary stalk. Efforts are made to preserve some normal pituitary superiorly against the diaphragma sellae and the stalk entry area. If no probable lesion is identified, we again mobilize both lateral lobes to the center of the exposure. Each lobe is explored internally, and we resect suspicious tissue if present. Still, there are a few caveats that must be considered.

In rare cases we move on to a radical subtotal or total hypophysectomy. The nature of the patient and his or her symptoms and comorbidities are critical aspects of the design and execution of this surgical plan. Given the intrinsic nature of these lesions, preservation of normal gland function is important for everyone, but particularly for young women or men who wish to have a family. On the other end of the spectrum, there are frail older patients with severe comorbidities, including intractable diabetes mellitus, uncontrolled hypertension, and other dangerous accompaniments of Cushing disease. The latter group may need a radical approach that may include hypophysectomy. Regardless, it is paramount to educate every patient about the disease, its prognosis if untreated, and the spectrum of treatment other than surgery that is available. They need to be informed about the methods of radiation therapy, including timing of effect and complications. ${ }^{41}$ They must know that medical therapies are available but not suitable for all patients, and are often accompanied by many other drug-related side effects. ${ }^{42}$ Finally, the surgical procedure must be described, including the goals of surgery, side effects, potential complications, initial postoperative course, and subsequent long-term follow-up, which is absolutely essential given the possibility of recurrence. ${ }^{10}$

\section{Corticotroph Hyperplasia and the Pathogenesis of Cushing Disease}

In 15 patients with symptoms and biochemical evidence of Cushing disease but in whom no tumor was found, 10 patients $(67 \%)$ with corticotroph hyperplasia were successfully treated with surgery. It is possible that the resected hyperplastic tissue was the causative pathology, but sam- 
A

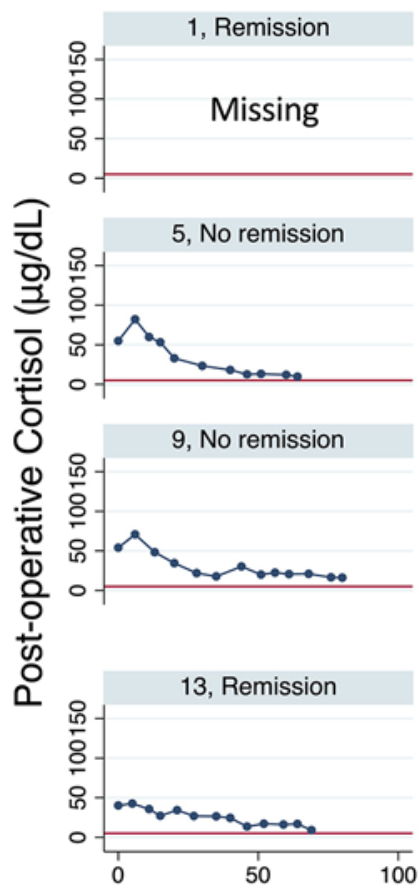

B

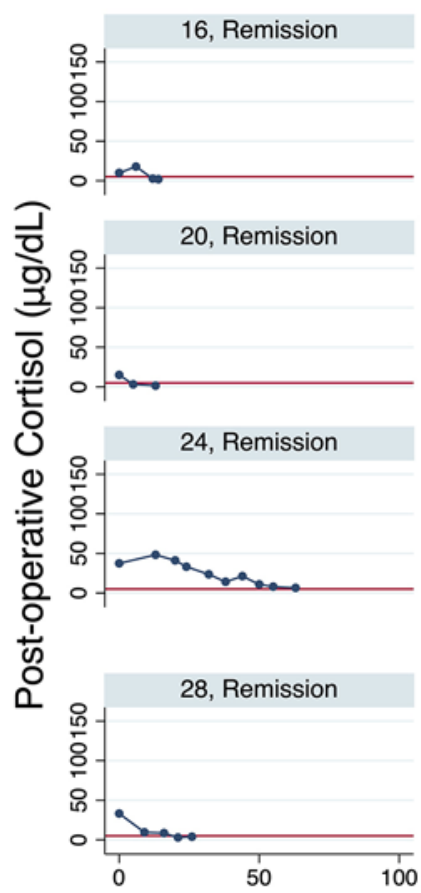

Hyperplasia

2, Remissio

Missing

6, No remission

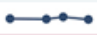

10 , No remission
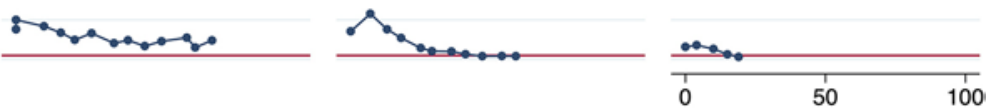

14, Remission

15, Remission
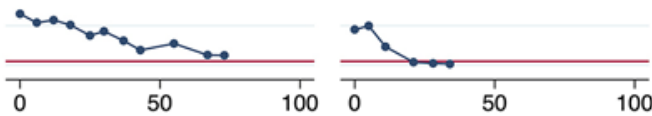

Post-operative Hours

\section{Adenoma}

17, Remission

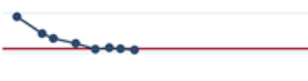

21, Remission

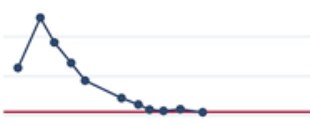

25, Remission

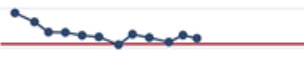

29, Remission

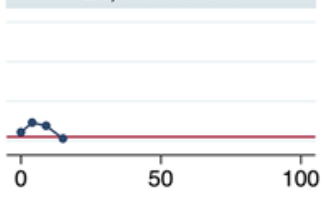

18, Remission

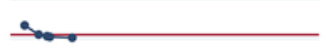

22, Remission
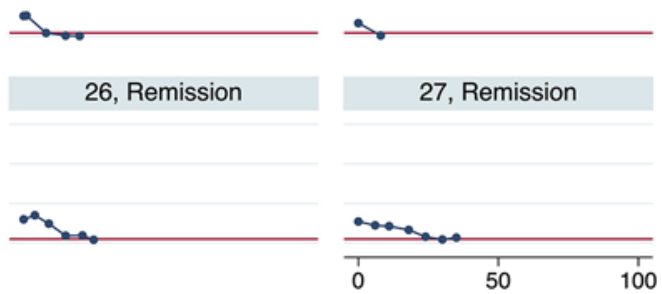

30 , No remission

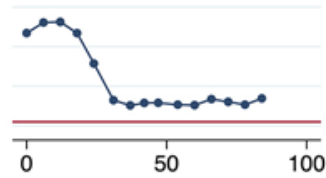

Post-operative Hours

FIG. 3. Postoperative serum cortisol dynamics in patients with corticotroph hyperplasia (A) and corticotroph adenoma (B). The case number corresponds to Table 1 for the hyperplasia group and is shared between Figs. 2 and 3 (both panels). Red lines are equal to a serum cortisol of $5 \mu \mathrm{g} / \mathrm{dL}$. A single patient is represented by cases 10 and 23 . This patient initially had hyperplasia on pathological analysis and did not enter remission. A subsequent operation a few months later resulted in remission and a frank adenoma was discovered on pathology. Figure is available in color online only. 


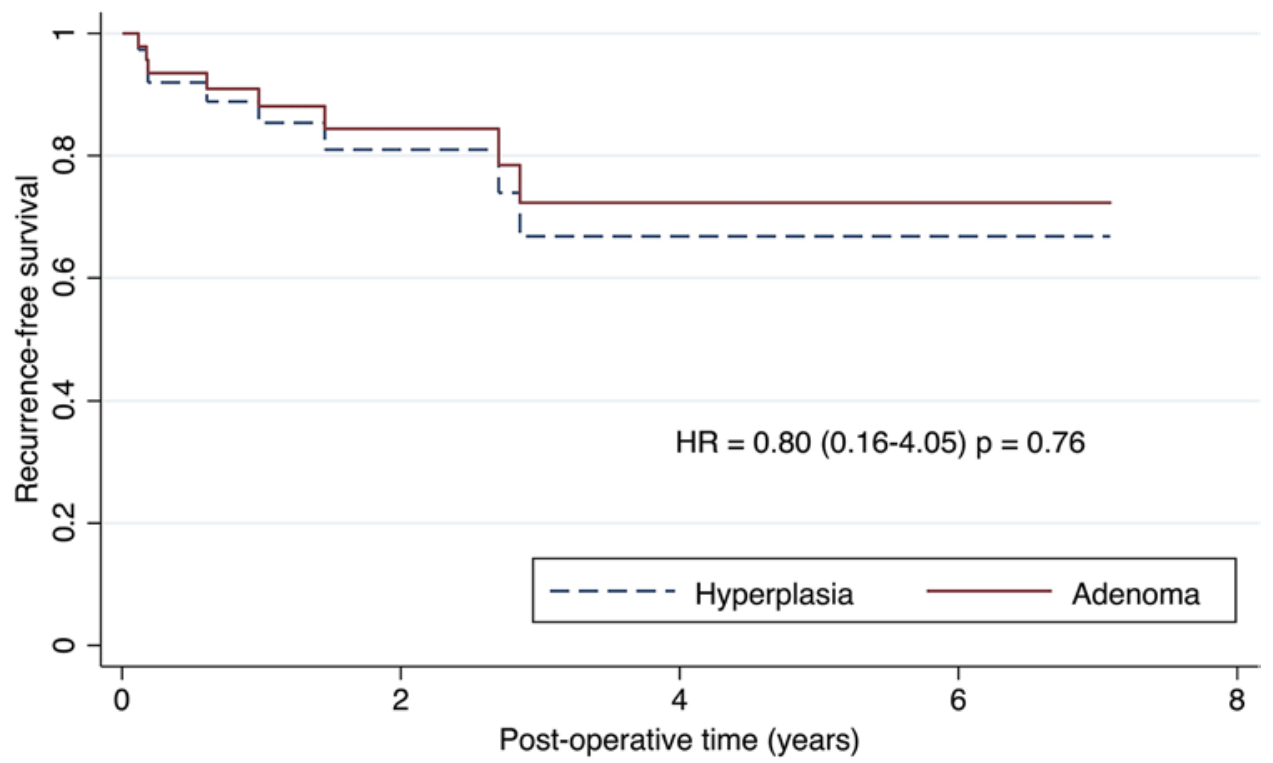

FIG. 4. Kaplan-Meier survival estimates for recurrence-free survival by pathological subtype adjusted for revision surgery (HR $0.80,95 \% \mathrm{Cl} 0.16-4.05 ; p=0.76)$. Figure is available in color online only.

pling error (e.g., due to tumor lost during surgery or tissue processing, or tissue infarction) is possible, which limits causative inference. Our findings also suggest that corticotroph hyperplasia cannot simply be the "normal" response of the pituitary to the specific needs of the body (e.g., undertreated hypocortisolism) $)^{20,29,30}$ or increased hypothalamic CRH drive as in primary corticotroph hyperplasia, ${ }^{15}$ primarily because of persistent remission comparable to patients with successfully treated adenomas (Fig. 4). The problem with ignoring the "hypothalamic" origin hypothesis is that recurrent genetic drivers have not consistently been identified in pituitary tumors..$^{43}$ USP 8 mutations, the most prevalent mutation in functional corticotroph adenomas, actually result in enhanced promoter activity of the proopiomelanocortin $(P O M C)$ gene. ${ }^{44}$ One can see the connection between enhanced promoter activity and sensitivity to $\mathrm{CRH}$, in which the $\mathrm{CRH}$ promotes the neoplastic condition associated with a USP8 mutation. Recent work has revealed that almost $30 \%$ of pituitary tumors have armlevel copy number alterations and widespread genomic disruptions, especially in functional tumors $(75 \%) .{ }^{45}$ Corticotroph hyperplasia probably represents a state in which there is a fixed pathological imbalance between the hormonal feedback mechanisms and cellular machinery, and therefore it may be a neoplastic precursor that originates at either the central (hypothalamic) or epigenetic level. Cushing disease represents a unique neoplastic process, or "biological malignancy," because the pathology depends on both cell function and cytology. ${ }^{20}$

\section{Limitations of the Study}

This study presents several limitations. The lack of consensus about the diagnosis makes outside blinded review of pathology unfeasible. Nonetheless, we highlight our own valuable learning experience over the years. Three patients with hyperplasia had missing cortisol data, and 2 patients had missing MRI data. Selection bias was possible in patients with inadequate or unrepresentative tissue samples, and from incomplete follow-up. Information bias was possible during measurement or reporting of the variables in the electronic records. Finally, the study was underpowered, and a larger sample size may show a difference in outcomes between the groups.

\section{Conclusions}

Our findings suggest an association between biochemically proven Cushing disease and histopathologically proven corticotroph hyperplasia. In patients suspected to have pituitary Cushing disease, the diagnosis of corticotroph hyperplasia may be supported by focal or diffusely expanded acini with retained reticular architecture and predominant ACTH staining within the expanded acini. Imaging and operative findings can be ambiguous, and thus, compared to typical adenomas with a pseudocapsule, the surgical approach is more nuanced. Nevertheless, if treated appropriately, biochemical outcomes may be similar.

\section{Acknowledgments}

Drs. Catalino and Laws receive support from the Brigham and Women's Hospital Research Imaging Core for "Quantifying Cerebral Network Dynamics and Neuropsychological Outcomes in Cushing Disease."

\section{References}

1. Burke CW, Adams CBT, Esiri MM, et al. Transsphenoidal surgery for Cushing's disease: does what is removed determine the endocrine outcome? Clin Endocrinol (Oxf). 1990; 33(4):525-537.

2. Robert F, Hardy J. Cushing's disease: a correlation of radiological, surgical and pathological findings with therapeutic results. Pathol Res Pract. 1991;187(5):617-621. 
3. Sheehan JM, Lopes MB, Sheehan JP, et al. Results of transsphenoidal surgery for Cushing's disease in patients with no histologically confirmed tumor. Neurosurgery. 2000;47(1): 33-39.

4. Pouratian N, Prevedello DM, Jagannathan J, et al. Outcomes and management of patients with Cushing's disease without pathological confirmation of tumor resection after transsphenoidal surgery. J Clin Endocrinol Metab. 2007;92(9): 3383-3388.

5. Lamberts SWJ, Stefanko SZ, de Lange SA, et al. Failure of clinical remission after transsphenoidal removal of a microadenoma in a patient with Cushing's disease: multiple hyperplastic and adenomatous cell nets in surrounding pituitary tissue. J Clin Endocrinol Metab. 1980;50(4):793795.

6. Kovacs K, Horvath E, Coire C, et al. Pituitary corticotroph hyperplasia preceding adenoma in a patient with Nelson's syndrome. Clin Neuropathol. 2006;25(2):74-80.

7. Jagannathan J, Smith R, DeVroom HL, et al. Outcome of using the histological pseudocapsule as a surgical capsule in Cushing disease. J Neurosurg. 2009;111(3):531-539.

8. Tyrrell JB, Brooks RM, Fitzgerald PA, et al. Cushing's disease. Selective trans-sphenoidal resection of pituitary microadenomas. N Engl J Med. 1978;298(14):753-758.

9. Salassa RM, Laws ER Jr, Carpenter PC, Northcutt RC. Transsphenoidal removal of pituitary microadenoma in Cushing's disease. Mayo Clin Proc. 1978;53(1):24-28.

10. Patil CG, Prevedello DM, Lad SP, et al. Late recurrences of Cushing's disease after initial successful transsphenoidal surgery. J Clin Endocrinol Metab. 2008;93(2):358-362.

11. Sheithauer BW, Horvath E, Lloyd RV, Kovacs K. Pituitary hyperplasia. Pathol Case Rev. 1998;3(6):281-289.

12. Lopes MBS. The 2017 World Health Organization classification of tumors of the pituitary gland: a summary. Acta Neuropathol. 2017;134(4):521-535.

13. Carey RM, Varma SK, Drake CR Jr, et al. Ectopic secretion of corticotropin-releasing factor as a cause of Cushing's syndrome. A clinical, morphologic, and biochemical study. $N$ Engl J Med. 1984;311(1):13-20.

14. Shahani S, Nudelman RJ, Nalini R, et al. Ectopic corticotropin-releasing hormone $(\mathrm{CRH})$ syndrome from metastatic small cell carcinoma: a case report and review of the literature. Diagn Pathol. 2010;5(56):56.

15. Young WF Jr, Scheithauer BW, Gharib H, et al. Cushing's syndrome due to primary multinodular corticotrope hyperplasia. Mayo Clin Proc. 1988;63(3):256-262.

16. Biller B, Klibanski A, Koenig J, Martin JB. Diagnostic dilemmas in the management of hypothalmic-pituitary-adrenal disorders. Ann N Y Acad Sci. 1987;512:338-350.

17. Asa SL. The role of hypothalamic hormones in the pathogenesis of pituitary adenomas. Pathol Res Pract. 1991;187(5): 581-583.

18. Nieman LK, Biller BMK, Findling JW, et al. The diagnosis of Cushing's syndrome: an Endocrine Society clinical practice guideline. J Clin Endocrinol Metab. 2008;93(5): $1526-1540$.

19. Nieman LK, Biller BMK, Findling JW, et al. Treatment of Cushing's syndrome: an Endocrine Society clinical practice guideline. J Clin Endocrinol Metab. 2015;100(8):2807-2831.

20. Bloodworth JMB Jr. Assessment of the pituitary hyperplasia/ neoplasia interface. Pathol Res Pract. 1988;183(5):626-630.

21. Al-Gahtany M, Horvath E, Kovacs K. Pituitary hyperplasia. Hormones (Athens). 2003;2(3):149-158.

22. Semple PL, Vance ML, Findling J, Laws ER Jr. Transsphenoidal surgery for Cushing's disease: outcome in patients with a normal magnetic resonance imaging scan. Neurosurgery. 2000;46(3):553-559.

23. Horvath E, Kovacs K, Scheithauer BW. Pituitary hyperplasia. Pituitary. 1999;1(3-4):169-179.
24. Mete O, Asa SL. Precursor lesions of endocrine system neoplasms. Pathology. 2013;45(3):316-330.

25. Oldfield EH, Vance ML, Louis RG, et al. Crooke's changes in Cushing's syndrome depends on degree of hypercortisolism and individual susceptibility. J Clin Endocrinol Metab. 2015; 100(8):3165-3171.

26. Patil CG, Veeravagu A, Prevedello DM, et al. Outcomes after repeat transsphenoidal surgery for recurrent Cushing's disease. Neurosurgery. 2008;63(2):266-271.

27. Simmons NE, Alden TD, Thorner MO, Laws ER Jr. Serum cortisol response to transsphenoidal surgery for Cushing disease. J Neurosurg. 2001;95(1):1-8.

28. Srinivasan L, Laws ER, Dodd RL, et al. The dynamics of post-operative plasma ACTH values following transsphenoidal surgery for Cushing's disease. Pituitary. 2011;14(4): 312-317.

29. Kovacs K, Stefaneanu L, Horvath E, et al. Pituitary corticotroph adenoma in a woman with long-standing Addison's disease: a histologic, immunocytochemical, electron microscopic, and in situ hybridization study. Endocr Pathol. 1996; 7(1):91-97.

30. Zhou J, Ruan L, Li H, et al. Addison's disease with pituitary hyperplasia: a case report and review of the literature. Endocrine. 2009;35(3):285-289.

31. Mustila T, Keskinen P, Terho M, et al. Pediatric Cushing's disease due to pituitary hyperplasia.J Pediatr Endocrinol Metab. 2011;24(3-4):191-192.

32. Noctor E. Paediatric cyclical Cushing's disease due to corticotroph cell hyperplasia. BMC Endocr Disord. 2015;15:27.

33. Kuebber S, Ropte S, Hori A. Proliferation of adenohypophyseal cells into posterior lobe. Their normal anatomical condition and possible neoplastic potentiality. Acta Neurochir (Wien). 1990;104(1-2):21-26.

34. Starke RM, Reames DL, Chen CJ, et al. Endoscopic transsphenoidal surgery for Cushing disease: techniques, outcomes, and predictors of remission. Neurosurgery. 2013; 72(2):240-247.

35. Smith TR, Hulou MM, Huang KT, et al. Complications after transsphenoidal surgery for patients with Cushing's disease and silent corticotroph adenomas. Neurosurg Focus. 2015; 38(2):E12-E11.

36. Zaidi HA, Penn DL, Cote DJ, Laws ER Jr. Root cause analysis of diagnostic and surgical failures in the treatment of suspected Cushing's disease. J Clin Neurosci. 2018;53:153-159.

37. Prevedello DM, Pouratian N, Sherman J, et al. Management of Cushing's disease: outcome in patients with microadenoma detected on pituitary magnetic resonance imaging. $J$ Neurosurg. 2008;109(4):751-759.

38. Meij BP, Lopes MB, Vance ML, et al. Double pituitary lesions in three patients with Cushing's disease. Pituitary. 2000;3(3):159-168.

39. Trouillas J, Guigard M-P, Fonlupt P, et al. Mapping of corticotropic cells in the normal human pituitary. $J$ Histochem Cytochem. 1996;44(5):473-479.

40. Horvath E, Kovacs K, Lloyd RV. Pars intermedia of the human pituitary revisited: morphologic aspects and frequency of hyperplasia of POMC-peptide immunoreactive cells. Endocr Pathol. 1999;10(1):55-64.

41. Bunevicius A, Laws ER, Vance ML, et al. Surgical and radiosurgical treatment strategies for Cushing's disease. J Neurooncol. 2019;145(3):403-413.

42. Hinojosa-Amaya JM, Cuevas-Ramos D, Fleseriu M. Medical management of Cushing's syndrome: current and emerging treatments. Drugs. 2019;79(9):935-956.

43. Melmed S. Pathogenesis of pituitary tumors. Nat Rev Endocrinol. 2011;7(5):257-266.

44. Reincke M, Sbiera S, Hayakawa A, et al. Mutations in the deubiquitinase gene USP8 cause Cushing's disease. Nat Genet. 2015;47(1):31-38. 
45. Bi WL, Horowitz P, Greenwald NF, et al. Landscape of genomic alterations in pituitary adenomas. Clin Cancer Res. 2017;23(7):1841-1851.

\section{Disclosures}

Dr. Min receives clinical or research support for the study described (includes equipment or material) from Corcept.

\section{Author Contributions}

Conception and design: Catalino, Meredith, De Girolami, Min, Laws. Acquisition of data: Catalino, Meredith, De Girolami,
Tavakol. Analysis and interpretation of data: all authors. Drafting the article: Catalino. Critically revising the article: all authors.

Reviewed submitted version of manuscript: all authors. Approved the final version of the manuscript on behalf of all authors:

Catalino. Statistical analysis: Catalino, Tavakol. Administrative/ technical/material support: De Girolami, Laws. Study supervision: Catalino, Laws.

\section{Correspondence}

Michael P. Catalino: University of North Carolina Hospitals, Chapel Hill, NC. michael.catalino@unchealth.unc.edu. 